\title{
Relations between the Causative Factors of Waste and Their Preventive Measures in China Construction Sites
}

\author{
Sulala M.Z.F AL-Hamadani, Luo Qing, Guilong Peng, Miaocheng Weng \\ Key Laboratory of The Three Gorges Reservoir Region's Eco-Environment, Ministry of Education, \\ Chongqing University, China \\ Faculty of Urban Construction and Environmental Engineering, Chongqing University, China
}

\begin{tabular}{l} 
Article Info \\
\hline Article history: \\
Received Sep 14, 2014 \\
Revised Nov 17, 2014 \\
Accepted Nov 29, 2014 \\
\hline
\end{tabular}

\section{Keyword:}

Causative factors

China

Construction sites

Material waste

Preventive Measures

Relations

\begin{abstract}
Material waste has been considered as a major problem in the construction industry. Material waste not only has a negative impact on the success and efficiency of construction project, but also on construction cost, construction time, productivity and sustainability aspects. This paper aims to identify the major causative factors of material waste in China construction sites, their preventive measures and the relations between them. For this purpose, views of Chinese construction industry practitioners in Chongqing city were gathered by a questionnaire survey. The respondents were requested to rate a total of 34 causative factors of material waste and 9 preventive measures, which were gathered from previous literature. These causative factors were grouped into eight categories: Design, Handling, Procurement, Operation, Worker, Management, Site condition and External factors. The major causative factors of each category and preventive measures of waste were determined. Based on the identification of major factors and measures, the relations between them were also determined.
\end{abstract}

Copyright $@ 2014$ Institute of Advanced Engineering and Science. All rights reserved.

\section{Corresponding Author:}

Sulala M.Z.F. A.L-Hamadani,

Faculty of Urban Construction and Environmental Engineering,

Chongqing University,

Chongqing 400042, P. R. China.

Email: solalazaki85@yahoo.com

\section{INTRODUCTION}

Construction waste has become an important environmental problem of the construction industry in China. China is considered as one of the biggest producers of waste, in 2001 China produced approximately $30 \%$ of the world's municipal solid waste (MSW) [1]. The extensive building and infrastructure development programmes, including redevelopment of old districts has led to a significant increase in construction and demolition waste generation in the last three decades in China, which makes up about $40 \%$ of the overall solid waste [2]-[3]. A total of 400 million tons of construction waste is generated in China every year [3]. These figures show the pressing need for the country to change how to deal with construction waste, and adopt other waste practices other than disposal in a landfill. This research supports this change by Identifying the major causative factors of material waste, preventive waste minimization Measures and the relations between the factors and their preventive measures in China construction sites.

\section{BACKGROUND}

Waste in the construction industry has been the subject of interest for several researchers around the world in recent years. Construction waste can be defined as all those activities that produce costs, direct or indirect, and take time, resources or require storage, but do not add value or progress to the product [4]. 
Alternatively, a simple way has been introduced to define construction waste which is "that which can be eliminated without reducing customer value". It can be activities, resources, rules, etc [5].

Many factors contribute to the generation of material waste in construction sites. These factors were grouped under four categories: (1) design; (2) procurement; (3) handling of materials; and (4) operation [6]. Construction waste is generated from various sources in the whole process of implementing a construction project. Construction waste sources have been classified into design errors, procurement errors, materials handling errors, machine operation errors and residual or leftover scraps [7].

Waste minimization has been defined according to EPA as "any method that reduces the volume or toxicity of a waste that requires disposal" [8]. Waste minimization includes source reduction and recycling [9]. Source reduction was defined as any activity that reduces or eliminates the generation of waste at source, usually within a process, and recycling as the recovery and/or re-use of what would otherwise be a waste material [9]. It was emphasized that the reduction is the best and most efficient method for minimizing the generation of waste and eliminating many of the waste disposal problems [5].

\section{RESEARCH METHODS}

\subsection{Data Collection Methods}

Thirty-four (34) causative factors of construction material waste generation as listed in Table 1, and nine (9) preventive waste minimization measures from the following references [9]-[10], [22], [25], which have been extensively studied were extracted from the literature. Both factors and measures were pre-tested in a pilot study using interviews and questionnaire involving seven selected construction experts to evaluate their applicability to the current study. Two of the experts were from contractors, three were from on-site supervision companies, and two from a construction research institute in the city. Most of them demonstrated in depth understanding and knowledge of both the factors and measures extracted from the literature for the study. They agreed with the applicability of the selected factors and measures to the current study. To reach the aim of this study, a structured questionnaire survey was conducted. The questionnaire was divided into three sections. The first part sought information about the respondents' profile, in the second and third part, respondents were requested to evaluate the 34 individual factors based on their category and the 9 measures in terms of their importance.

The level of importance for the 34 factors and 9 measures was measured on a 5-point Likert scale, where 5 indicated extremely important, 4 important, 3 neutral, 2 unimportant, and 1 negligible. The questionnaire survey (written in Chinese) was conducted in Chongqing over a three-month period from January to March 2014. A total of 90 questionnaires were distributed through direct visits to the construction firms and sites. The target groups were randomly selected from industry practitioners. Finally a total of 80 valid responses were received, representing an overall response rate of $89 \%$, which is considered satisfactory [11].

The respondents included 45 engineers comprising office and supervision engineers, 11 experienced project managers, 10 Construction Technicians, 5 Architects, and 9 Quantity Surveyors. Most of the respondents were well-experienced professionals in construction practice since the majority of them (80 percent) have more than ten years' working experience in the construction industry (see Figure 1).

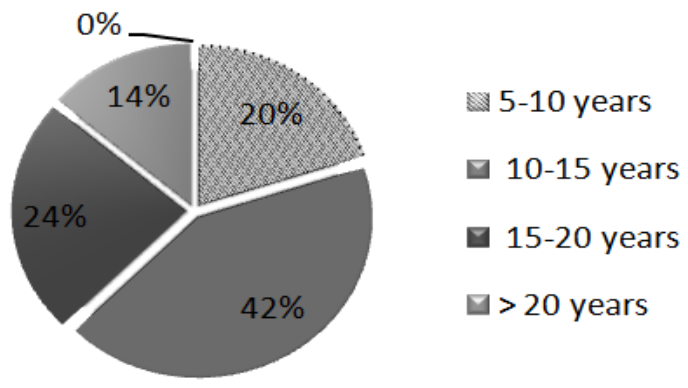

Figure 1. Respondent's experience in the construction industry

\subsection{Data Analysis Methods}

The reliability test was conducted on the data to measure its stability and consistency. In this test, the index Cronbach's coefficient alpha was calculated in order to indicate the reliability of the data. Cronbach's alpha reliability coefficient normally ranges between 0 and 1 . The closer Cronbach's coefficient

Relations between the Causative Factors of Waste and Their Preventive... (Sulala M.Z.F AL-Hamadani) 
alpha value to 1 the higher the internal consistency reliability of the data [12]. The result of this test is 0.912 , indicating that the data collected are highly reliable.

Table 1. Causative factors of construction material waste

\begin{tabular}{|c|c|c|c|c|c|c|c|c|c|c|c|}
\hline No & Source & Causative factors of construction material & & & & & eferen & & & & \\
\hline 1 & & Frequent design changes & [5] & [15] & [16] & [17] & [18] & [19] & [20] & [21] & \\
\hline 2 & Desion & Mistakes and Errors in design & [2] & [6] & [7] & [14] & [16] & [17] & [18] & [19] & [22] \\
\hline 3 & & Complexity of detailing in the drawings & [5] & [6] & & & & & & & \\
\hline 4 & & Lack of information in the drawings & [5] & [15] & [16] & [17] & [23] & & & & \\
\hline 5 & & Damage during transportation to site/on site & [2] & [6] & [15] & [19] & & & & & \\
\hline 6 & Handling & Inappropriate storage leading to damage & [2] & [6] & [7] & [15] & [16] & [19] & [21] & [22] & [23] \\
\hline 7 & & Wrong material handling & [5] & [6] & [7] & [15] & [16] & [20] & [21] & [22] & [23] \\
\hline 8 & & Ordering errors & [2] & [6] & [7] & [14] & [19] & [22] & & & \\
\hline 9 & Procurement & $\begin{array}{l}\text { Products not in compliance with } \\
\text { specification }\end{array}$ & [5] & [19] & & & & & & & \\
\hline 10 & & Mistakes in quantity surveys & [5] & [6] & [15] & [21] & & & & & \\
\hline 11 & & $\begin{array}{l}\text { Damage to work done caused by subsequent } \\
\text { trades }\end{array}$ & [16] & [19] & [23] & [24] & & & & & \\
\hline 12 & Operation & $\begin{array}{l}\text { Use of incorrect material, thus requiring } \\
\text { replacement }\end{array}$ & [2] & [16] & [19] & [23] & & & & & \\
\hline 13 & & Poor workmanship. & [22] & [25] & [26] & & & & & & \\
\hline 14 & & Mistakes during construction. & [2] & [24] & & & & & & & \\
\hline 15 & & Insufficient training for workers & [2] & [15] & [26] & & & & & & \\
\hline 16 & Wrato & Shortage of skilled workers & [5] & [16] & [23] & [26] & & & & & \\
\hline 17 & WOIRCT & Workers' mistakes & [2] & [6] & [7] & [14] & [19] & [20] & [25] & & \\
\hline 18 & & Rework due to workers' mistake & [5] & [6] & [25] & & & & & & \\
\hline 19 & & Poor site management and supervision & [2] & [16] & [17] & [18] & [22] & [24] & & & \\
\hline 20 & & Lack of strategy to waste minimization & [25] & & & & & & & & \\
\hline 21 & & Lack of on site waste management plans & [5] & [19] & [24] & [25] & & & & & \\
\hline 22 & & Inadequate planning and scheduling & [6] & [7] & [22] & [23] & & & & & \\
\hline 23 & Morat & Incompetent subcontractors & [2] & [6] & [7] & & & & & & \\
\hline 24 & & Lack of coordination among parties & [5] & [15] & [16] & & & & & & \\
\hline 25 & & Scarcity of equipment or Outdated equipment & [5] & [6] & [16] & [18] & [23] & & & & \\
\hline 26 & & Inappropriate construction methods & [16] & [21] & [23] & & & & & & \\
\hline 27 & & Slow information flow between the parties & [6] & [15] & [19] & & & & & & \\
\hline 28 & & Unnecessary inventories & [16] & & & & & & & & \\
\hline 29 & & Poor site condition & [16] & [18] & [23] & & & & & & \\
\hline 30 & condition & Difficult access in construction sites & [18] & & & & & & & & \\
\hline 21 & & Lighting problem in night shaft operations & [18] & & & & & & & & \\
\hline 32 & & Accidents & [6] & [16] & [17] & [19] & [22] & & & & \\
\hline 33 & $\begin{array}{l}\text { External } \\
\text { factors }\end{array}$ & Effect of weather & [5] & [6] & [17] & [19] & [22] & & & & \\
\hline 34 & & Unpredictable local conditions & [5] & [13] & & & & & & & \\
\hline
\end{tabular}

The data were then analyzed by using statistical analysis techniques including ranking analysis and correlation test. These research activities were facilitated with the aid of SPSS 12.0. The process of data analysis is interpreted as follows.

First, the relative importance of all factors and measures was examined by ranking them based on their mean values and standard deviation. It is worth highlighting that only those factors and measures with mean values that are greater than 3.000 were recognized as critical causative factors and preventive measures of material waste. Then an investigation was conducted in this study to determine the correlation between the 
major factors and the measures. To determine the correlation, the Spearman Correlation approach has been run, which is the most appropriate statistical test when assessing ordinal data that are related to more than one attribute [13]. In statistics, the value of the correlation coefficient varies between +1 and -1 . When the value of the correlation coefficient lies around \pm 1 , strong correlation between the two variables is considered. When the value of the correlation coefficient goes towards 0 , weak correlation between the two variables is considered [13].

\section{DATA FINDINGS AND ANALYSIS}

\subsection{Major Causative Factors of Material Waste}

The results of the major causative factors in each category are shown in Table 2. Causative factors were grouped into the eight categories: Design, Handling, Procurement, Operation, Worker, Management, Site condition and External factors. The significance of the causative factor in each category was determined based on the mean value and standard deviation. The factor that has the highest mean value of each category was identified as a major factor within that category.

Table 2. Major causative factors based on their category

\begin{tabular}{|c|c|c|c|}
\hline 5. Category & Major causative factors & Mean & Std. Deviation \\
\hline Design & Mistakes and Errors in design & 3.73 & 1.30 \\
\hline 7. Handling & Inappropriate storage leading to damage & 3.82 & 1.16 \\
\hline 8. Procurement & Products not in compliance with specification & 3.55 & 1.31 \\
\hline Operation & Poor workmanship. & 3.97 & 1.01 \\
\hline Worker & Insufficient training for workers & 4.31 & 0.95 \\
\hline 10 Management & Lack of on site waste management plans & 3.26 & 1.04 \\
\hline 11 Site condition & Difficult access in construction sites & 3.08 & 0.96 \\
\hline 12. External factors & Effect of weather & 3.00 & 1.00 \\
\hline
\end{tabular}

\subsection{Preventive Waste Minimization Measures}

The analysis on material waste minimization measures is shown in Table 3. The analysis shows that the top four measures focus on waste prevention. These measures are: Vocational training and heightened awareness, Ordering just what is needed of material, Efficient coordination between store and construction personnel, and Using materials before expiry dates. Undoubtedly, this is a prioritized option to most if not all firms. It is better to prevent waste from the beginning than dealing with it after it is generated.

The two measures that the analysis presents to be less considerably implemented in the industry are: employment of on-site waste management personnel and recycling of waste materials on-site or off-site. Employment of on-site waste management personnel was seen as the least preferred option for contractors because it would be a cost adding item. Furthermore, recycling is rarely carried out because of the lack of recycling facilities and mature market for trading recycled materials in China Chongqing city.

Table 3. Ranking of preventive waste minimization measures

\begin{tabular}{lccc}
\hline Preventive waste minimization measures & Mean & Std. Deviation & Rank \\
\hline Vocational training and heightened awareness & 4.80 & 0.54 & 1 \\
Ordering just what is needed of material & 4.02 & 0.56 & 2 \\
Efficient coordination between store and construction personnel & 3.62 & 0.78 & 3 \\
Using materials before expiry dates & 3.51 & 0.80 & 4 \\
Effective construction management practices & 3.35 & 0.89 & 5 \\
Vigilant on site supervision system & 3.05 & 1.01 & 6 \\
Use of Low-waste construction technologies & 2.44 & 0.62 & 7 \\
Employment of on-site waste management personnel & 2.05 & 0.77 & 8 \\
Recycling of waste materials on-site or off-site & 1.67 & 0.70 & 9 \\
\hline
\end{tabular}

\subsection{Relations between the Causative Factors and Preventive Measures}

As shown in Table 4, the strength of the relationship between the determined major causative factors obtained from Table 2 and the ranking of the preventive measures in the Table 3 was tested. To determine the strength, the Spearman correlation approach was adopted. The values of correlation coefficient were obtained by analyzing the already-existing data into SPSS 12.0. The null hypothesis was set as: "there was no significant relationship between the ranking of the preventive measures and the correspondent causes involving these measures". The null hypothesis was accepted, because $\alpha$-value is less than (0.01). 
Table 4. Correlation test between causative factors and preventive measures

\begin{tabular}{|c|c|c|c|}
\hline Causative factor of waste & Preventive measure & $\alpha$-value & $\begin{array}{c}\text { Correlation } \\
\text { Coefficient (r) }\end{array}$ \\
\hline Lack of on-site waste management plan & Effective construction management practices & 0.001 & $+0.722 * *$ \\
\hline Insufficient training for workers & Vocational training and heightened awareness & 0.000 & $+0.657 * *$ \\
\hline Inappropriate storage leading to damage & Efficient coordination between store and construction personnel & 0.003 & $-0.557 * *$ \\
\hline $\begin{array}{l}\text { Poor workmanship } \\
* * \text { Correlation is significant at the } 0.01 \text { le }\end{array}$ & $\begin{array}{l}\text { Vigilant on site supervision system } \\
\text { el (2-tailed) }\end{array}$ & 0.002 & $-0.602 * *$ \\
\hline
\end{tabular}

The positive correlation between the ranking of 'Lack of on-site waste management plan' and ' Effective construction management practices' can be explained that 'Lack of on-site waste management plan' factor is considered as a significant factor because the on-site waste management plans were not sufficiently applied on Chinese construction sites, and 'good construction management practices' measure needed to be applied. In addition, the positive correlation between the ranking of 'Vocational training and heightened awareness' and 'Insufficient training for workers' can be illustrated that this measure was not effectively implemented because insufficient training is considered as a high contributor to waste.

The negative correlation between the rankings of 'Vigilant on-site supervision system' and 'Poor workmanship; and between 'Inappropriate storage leading to damage' and 'Efficient coordination between store and construction personnel' indicates that the two factors are considered of the least contribution to the generation of material waste because of the repeated implementation of the proper measures.

\section{CONCLUSION}

This paper has investigated the findings from a questionnaire survey conducted in China construction sites Chongqing city looking at the identification of major causative factors of material waste and preventive minimization measures, in addition to the relations between them.

These findings will give a better understanding to the Chinese construction industry practitioner about the major causative factors of material waste during the construction process, so that considerable efforts can be devoted to applying the relevant minimization measures as a first line of defense in a campaign to reduce construction material waste.

\section{ACKNOWLEDGEMENTS}

This work was supported by the Faculty of Urban Construction and Environmental Engineering, Chongqing University, Chongqing, 400045, P. R. China.

\section{REFERENCES}

[1] Dong S. S., et al., "Municipal solid waste management in China: using commercial management to solve a growing problem," Utilities Policy journal, 2001, Vol. 10, No. 1, pp. 7-11.

[2] Wang J. Y., et al., "An investigation of construction wastes: an empirical study in Shenzhen," Journal of Engineering, Design and Technology, 2008, Vol. 6, No. 3, pp. 227-36.

[3] Lu K. A., "The actuality and integrate using of China's construction wastes," Journal of Construction Technology, 1999, Vol. 128, No. 5, pp. 44-45.

[4] Koskela L., "Application of the new production philosophy to construction," Technical Report No. 72, CIFE, Stanford University, Calif, USA, 1992.

[5] Polat G., et al., "Waste in Turkish Construction: Need for Lean Construction Techniques," Twelfth Annual Conference of the International Groupfor Lean Construction (IGLC-12), Elsinore, Denmark, 2004.

[6] Ekanayake L. L., et al., "Construction Material Waste Source Evaluation," In: Proceedings of the 2nd Southern African Conference on Sustainable Development in the Built Environment, Pretoria, South Africa, 2000.

[7] Gavilan R. M., et al., "Source evaluation of solid waste in building construction," Journal of Construction Engineering and Management," 1994, Vol. 20, No. 3, pp. 536-552.

[8] Environmental Protection Agency of USA, "Solid Waste and Emergency Response," EPA-530-F-00-001, United States, 2000.

[9] Begum R. A., et al., "Implementation of waste management and minimization in the Malaysian construction industry," Conservation and Recycling, 2006, Vol. 51, pp. 190-202.

[10] Shen L. Y., et al., "Implementation of environmental management in the Hong Kong construction industry," International Journal of Project Management, 2002, Vol. 20, No. 7, pp. 535- 543.

[11] Moser C. A., et al., "Survey methods in social investigation," London: Heinemann Educational, 1971.

[12] Sekaran U., et al., "Research methods for business: A skill building approach," $5^{\text {th }}$ edition. London: John Wiley \& Sons, 2010. 
[13] Naoum S., "Dissertation Research and Writing for Construction Students," $2^{\text {nd }}$ Ed., Oxford: ButterworthHeinemann, 2007.

[14] Macozoma D. S., "Construction Site Waste Management and Minimization," International Council for Research and Innovation in Building and Construction $(C I B) /(C S I R)$ Building and Construction Technology, Report No. BOU/C361, Pretoria, South Africa, 2002.

[15] Garas G. L., et al., "Materials Waste in the Egyptian Construction Industry," Proceedings of the ninth Annual Conference of The International Group for Lean Construction IGLC-9, Singapore, 2001.

[16] Alwi S., et al., "Waste in the Indonesian Construction Project," In: Proceedings of the $1^{\text {st }}$ International Conferences of CIB W107 - Creating a Sustainable Construction Industry in Developing Countries, South Africa, 2002, pp. 305-315.

[17] Alwi S., et al., "Non Value-Adding Activities in Australian Construction Projects," In International Conference on Advancement in Design, Construction, Construction Management and Maintenance of Building Structure, 2002.

[18] Zhao Y., et al., "Relationship between Productivity and Non Value-Adding Activities," In: Proceeding of the 11th annual conference of the international group for lean construction, Blacksburg, Virginia, USA, 2003.

[19] Bossink B. A. G., et al., "Construction waste: Quantification and source evaluation," Journal of Construction Engineering and Management, 1996, Vol. 122, No. 1, pp. 55-60.

[20] Lu W., et al., "An empirical investigation of construction and demolition waste generation rates in Shenzhen city, South China," Waste management, 2011, Vol. 31, No. 4, pp. 680-687.

[21] Wahab A. B., et al., "An evaluation of waste control measures in construction industry in Nigeria," African Journal of Environmental Science and Technology, 2011, Vol. 5, No. 3, pp. 246-254.

[22] Faniran O. O., et al., "Minimizing Waste on Construction Project Sites," Journal of Engineering, Construction and Architectural Management, 1998, Vol. 5, No. 2, pp. 182-188.

[23] Nazech E. M., et al., "Identification of construction waste in road and highway construction projects," Proceedings Eleventh East Asia-Pacific Conference on Structural Engineering and Construction (EASEC-11), Taipei, Taiwan, 2008.

[24] Urio A. F., et al., "Solid waste management strategy in Botswana: The reduction of construction waste, Journal of the South African Institution of Civil Engineering, 2006, Vol. 48, No. 2, pp. 18-22.

[25] Poon C. S., et al., "A Guide for Managing and Minimizing Building and Demolition Waste." The Hong Kong polytechnic University, 2001.

[26] Lu W. S., et al., "Exploring critical success factors for waste management in construction projects of China," Resources, Conservation and Recycling, 2010, Vol. 55, No. 2, pp. 201-202 